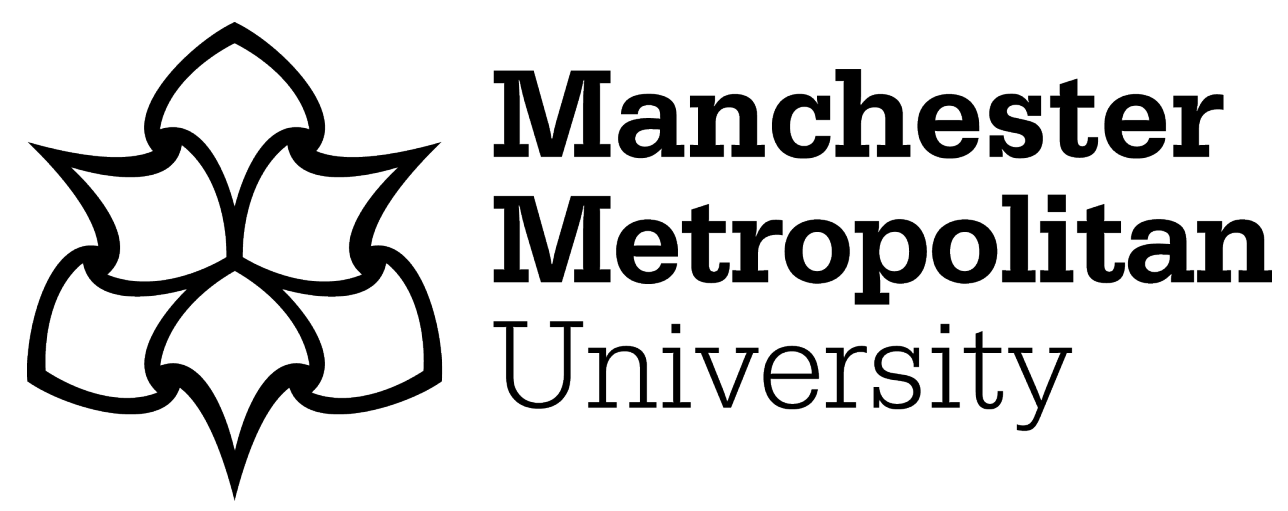

Rousell, DS, Cutcher, Alexandra, Cook, Peter and Irwin, Rita (2019) Propositions for an Environmental Arts Pedagogy: A/r/tographic experimentations with movement and materiality. In: Research Handbook on Childhoodnature: Assemblage of Childhood and Nature Research. Springer International Handbooks of Education . Springer. ISBN 978-3-319-67285-4

Downloaded from: https: //e-space.mmu.ac.uk/620896/

Version: Accepted Version

Publisher: Springer

Please cite the published version 


\section{Propositions for an Environmental Arts Pedagogy: A/r/tographic experimentations with movement and materiality}

This chapter works through a series of methodological experimentations with movement and materiality in order to explore the potentials of environmental arts pedagogies. We address the question of what environmental arts pedagogies might come to look like in the ever-changing contexts of children's social and environmental worlds. This leads us to engage with choreographic movement and the heterogeneous materialities of place through differential flows of human and non-human agencies as they come to co-compose pedagogical encounters. In doing so, we draw on new materialist accounts of matter as agentic, fluid and dynamic, movement as a choreographic architecting of experience, and $\mathrm{a} / \mathrm{r} /$ tographic approaches to pedagogical engagement and embodied practice. We acknowledge that the impetus for movement generation may come from a multitude of sources, however in this project we develop a series of experimentations with movement, materiality, environment, art, and pedagogy through $\mathrm{a} / \mathrm{r} /$ tographic fieldwork. These propositional encounters generated four artistic processes as they emerged through the concepts of 'corridors', 'flight', 'viscosity' and 'construction'. In teasing out the implications of these concepts for an environmental arts pedagogy, we combine imagery and text to both render and diagram the movement of bodies, materials and environments in passage through each of these four conceptual enactments. This leads us to develop a series of propositions for environmental arts pedagogy based on our creative research process. In doing so, we aim to retain the radical openness and contingency of what environmental arts pedagogies might come to look like in response to the rapidly changing material conditions of our times.

Keywords: environmental arts pedagogies; movement; new materialism; arts-based research.

\section{Introduction}

In this chapter we address the need for environmental arts pedagogies that are responsive to the rapidly changing material conditions of children's social and environmental worlds. Children are growing up in increasingly precarious times, as rates of anthropogenic climate change, loss of biodiversity, human overpopulation, ubiquitous computation, and biotechnological innovation continue to advance and proliferate with alarming frequency (Malone, 2016). How might environmental arts pedagogies become more attuned and responsive to the material conditions of contemporary life? What role might environmental arts pedagogies come to play in the lives of children in these times of accelerating change? This chapter responds to these questions through a series of $a / r /$ tographic experimentations that explore the relationship between movement and materiality through new materialist theory and artistic practice. As a methodology that operates through relational practices of artmaking, researching, and teaching/learning (Irwin \& Springgay, 2008), we take up $a / r /$ tography as an ecology of practices in which human and nonhuman agencies are always entangled in distributed processes of co-composition, negotiation, and constructive functioning (Stengers, 2005). This chapter thus contributes to an emerging body of scholarship that uses new materialist theories to explore the relational spaces between art, environment, and pedagogy (see, for instance, Garoian, 2012; Rousell \& Fell, in press; Springgay \& Rotas, 2015).

Our focus on the environmentality of art as a pedagogical encounter urges us to think and work outside the limitations of human(ist) discourse and identity, exploring the ways that 'art also does its work without human intervention, activating fields of relation that are environmental or ecological in scales of intermixings that may include the human but don't depend on it' (Manning, 2015, p. 72). We 
therefore propose a shift in the emphasis and enactment of $a / r /$ tography towards more-than-human processes that cut across bodies, environments, materials, concepts, surfaces, feeling, sensations and ideas. This is necessarily an ethical as much as an aesthetic shift, as it involves a 'politics of experimentation that is never fully intelligible or known' (Springgay \& Rotas, 2015, p. 552), and brings an ethico-aesthetic paradigm to bear on the embodied and emplaced practices of environmental arts pedagogy (Guattari, 1995).

In the sections that follow, we begin by contextualising our approach to environmental arts pedagogy within new materialist theorisations of materiality and movement as forces that exceed human intentionality, knowledge, and control. We then introduce the $\mathrm{a} / \mathrm{r} /$ tographic fieldwork that we used to develop a series of creative experimentations with concepts of 'corridor', 'flight', 'viscosity', and 'construction', each of which explores the entanglement of matter and movement in different ways. This is followed by a series of visual and semiotic renderings that work through each of these concepts in turn, drawing on the images, field notes, and theorisations that emerged in and through our $\mathrm{a} / \mathrm{r} /$ tographic fieldwork. These renderings are followed by a diagrammatic analysis of the four conceptual practices. This analytic process leads us to develop a series of propositions for an environmental arts pedagogy that integrates embodied movement and materiality with the flight of the speculative imagination.

\section{Matter, Movement, Art}

Our approach to developing environmental arts pedagogies builds on new materialist theorisations that position movement and materiality as agentic forces in the production of works of art and associated learning experiences (Bolt, 2013; XXXX \& Fell, in press). New materialism is a strand of speculative philosophy and theory that has emerged over the last decade. While new materialisms encompass a wide variety of theoretical positions, approaches, and investments, their ontological schemes generally hold that all of existence is embedded in some type of material substrate, including not only material objects and bodies but also conceptual, discursive, semiotic and incorporeal constructs, ideations and projections (Coole \& Froste, 2010). As Coole and Froste (p. 10) note, new materialist philosophies outline a political ecology in which 'matter is no longer imagined... as a massive, opaque plenitude but is recognised instead as indeterminate, constantly forming and reforming in unexpected ways'. In positioning matter as a force that both materializes and expresses the potentials of nature's dynamic indeterminacy, new materialism ultimately 'sees its task as creating new concepts and images of nature that affirm matter's immanent vitality' (p. 8). This also confirms new materialism's compatibility with Indigenous ontologies (e.g. Hunt, 2014) that acknowledge the vitality and agency of animals, plants, metals, minerals and elemental forces such as wind, rain and electricity (Ingold, 2011).

While new materialism has its roots in feminist-materialist thought associated with post-structuralism (Alaimo \& Heckman, 2008) and ecofeminism (Mies \& Shiva, 1993), it explicitly breaks with dialectical, Marxist traditions predicated on social constructivism, deconstruction, relativism and 'critical theory' more broadly (Braidotti, 2013). Instead, new materialisms tend to draw on fields such as quantum physics, the life sciences, and posthumanist philosophy to propose visionary and creative 'alternatives to critique' (Dolphjn \& van der Tuin, 2013, p. 14). In challenging the ongoing dominance of humanist and anthropocentric ontologies and practices, these emerging materialisms seek to develop new conceptual tools that are responsive to the changing social, technological, and environmental conditions of the contemporary world. While new materialist theory is having a timely impact in the arts, humanities, and sciences, the movement has also impacted significantly on the field of education, including the areas of environmental education (Malone, 2015), arts education (Rousell \& Fell, in 
press; Springgay \& Rotas, 2015) and post-qualitative methodologies for educational research (St. Pierre, 2016).

In developing a new materialist approach to environmental arts pedagogy, we build on recent scholarship that has theorised the materiality of creative practice beyond the limitations of representational and anthropocentric thought (Bolt, 2013; Tiainen, Konturri, \& Hongisto, 2015; Triggs \& XXXX, in press). Drawing on the work of theorist and physicist Karen Barad (2007), this involves a movement away from reflection as the core practice of teaching and learning through the arts. In lieu of reflexivity (an 'iterative mimesis' that produces reflections of reflections ad infinitum), Barad (p. 88) proposes a turn towards diffraction as a creative practice that is orientated towards patterns of difference. Rather than the 'self-referential glance back at oneself' associated with reflection and identity, diffraction attends to the interference patterns that are generated through the 'specific material entanglements' of heterogeneous agencies (ibid). The work of art, in this sense, is produced not by the agency of the individual artist, but through multiple agencies which disrupt and interfere with one another within an 'ontologically heterogeneous field' of relations (Bennett 2010, p. 23). To learn through the arts, then, is to become entangled with 'the shared materiality of all things... of which we are all composed' (pp. 12-13). The work of art becomes a 'co-collaboration' in which 'matter as much as the human has responsibility for the emergence of art' (Bolt, 2013, p. 6). The question is to what extent the artist become 'attentive to, and responsive/responsible to, the specificity of material entanglements in their agential becoming' (Barad 2007, p. 91).

Studies of movement have also been central to new materialist scholarship in the arts, in which choreographic processes are seen to operate outside of human intentionality and knowledge (see Knight, 2016; Manning, 2013; Massumi, 2011). Movement is understood to be as ubiquitous and allencompassing as matter, as Manning (2013, pp. 13-14) writes:

Movement is everywhere, always, at all scales, speeds, and slownesses. There is never stability. And there can never be non-movement - even in what appears to be complete stillness there is a quality of movement-moving, force of form.

This makes choreography a more-than-human phenomenon that 'attends to the immanent field of relation that is part and parcel of an environment in-forming ... a self-generating practice of difference' (Manning, 2013, p. 76). In linking such distributed and ecological conceptions of movement with pedagogy, Knight (2016, p. 19) further describes how 'choreographic movement emerges as rhythmic through the effect of energy as it flows between diverse sensory, temporal, and material agents'. Choreographic movement thus becomes pedagogical in its capacity to 'initiate reactions and responses between agents that change course of direction, prompt reconsiderations, and adjust trajectories' (p. 25). We therefore see a profound connection between movement and materiality as primordial elements of the environmental arts, with pedagogy emerging as a choreographic force that brings movement and materiality together in ways that generate novel assemblages, environments, events, experiences, and ecologies of learning and participation.

\section{$\mathrm{A} / \mathrm{r} /$ tographic Fieldwork}

Drawing on this genealogy of thinking and practice in new materialist theory and artistic practice, we set out to design a series of experimentations that would unfold through collaborative $a / r / t o g r a p h i c$ fieldwork. For the last two decades, $a / r /$ tography has developed as an international methodology that operates in the dynamic interstices between the relational practices of artmaking, researching, and teaching/learning (Irwin \& Springgay, 2008). In taking up a/r/tographic fieldwork as an ecology of practices, we aimed to discard the all too human identities of artist/researcher/teacher in favour of a more distributed and environmental process of becoming (Stengers, 2005). We also sought to 
negotiate a consonant shift away from the calcified identities of the adult/teacher and child/learner, as captured within a closed system of dyadic stimulus and response. In foregrounding the immanent ethics of the event of encounter as the basis for environmental learning and art, we chose to pursue a tentative movement towards the learning environment itself as productive of new forms and

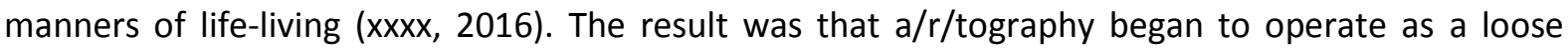
assemblage of framing practices that modulated the relations between elements of life/nature/environment/movement/matter, and worked to put theoretical concepts into play through creative experimentations with materials and media (Tiainen, Konturri, \& Hongisto, 2015).

Our starting point for the $a / r /$ tographic fieldwork was the question: How does movement come to matter in environmental arts pedagogies? This question was initially formulated through a series of research dialogues, in which we discussed the methodological, conceptual, and practical issues facing the field of arts education in the contemporary world. In order to investigate this problem through creative, philosophical and empirical experimentation, we firstly worked collaboratively to establish a series of enabling constraints. This allowed the research to emerge through a series of negotiations within a problematic field of entanglement. After a series of intensive dialogues, we settled on each of the following six protocols as the basis for our $\mathrm{a} / \mathrm{r} /$ tographic fieldwork:

1. draw on a concept from our own arts/educational/research practices in addressing the research question

2. design a creative research activity that explored our chosen concept

3. concepts and their associated activity designs would not be disclosed prior to their enactments on the day

4. Southern Cross University Gold Coast campus and surrounds (airport and beach) would serve as the context for these experimentations over the course of a single day

5. select a site for experimentation within this geographical location, thus forming the itinerary for our collective movements over the course of a single day

6. four activities would be followed by a period of discussion regarding the conceptual and material yields, provocations, pedagogies and movements instigated by the experience.

In foregrounding the process of 'concept as method' (Lenz Taguchi, 2016), we aimed to explore how the actual movement of thought occurs in/through/as matter, and how the non-discursive and affective capacities of art enable concepts to proliferate outside the limitations of human language and cognitive interpretation. By restricting prior knowledge of each other's concepts and activities, we sought to avoid the trap of a consensual framework that would have simultaneously delimited and 'answered' our research problem pre-emptively. Rather, our conceptual designs were formulated discretely as nodes of experimental knowledge practices within a problematic field that remained virtual/unknowable (Deleuze, 1994). This allowed for a continuous tension between the structures of our individual 'set ups', and the ruptures, immediations, resonances and dissonances that emerged spontaneously between them. Each of the conceptual designs also operated as a machinic 'suspension' of concrete procedures/constraints and abstract indeterminacies with regards to the qualitative enactments they engendered internally. We could say that each of the activities exhibited intensive properties particular to its design (both concrete and abstract), and extensive properties particular to its emergent relationships with the other three (both virtual and actual). It was in this sense that the conceptual framing of the research problem took shape through a series of pedagogical experimentations, in which semi-structured conceptual designs mobilised an emergent theoretical 
framework that only became perceptible in and through its enactment and subsequent articulation. We thus allowed each concept to materialise through the enactment of the research design as an emergent $\mathrm{a} / \mathrm{r} /$ tographic process. In doing so, we aimed to 'strengthen the concept's abilities to reach beyond the generalising classificatory tendencies of language toward affecting how the world's specificities are felt, perceived and lived with' (Tiainen, Konturri, \& Hongisto, 2015, p. 16). The following four sections of the chapter provide a visual and textual rendering of each of the four concepts as they were set into motion through the $\mathrm{a} / \mathrm{r} /$ tographic fieldwork process.

\section{Corridors}

We begin our investigation into movement and matter along a strip of Kirra Beach that stretches for miles along Queensland's Gold Coast. The beach provides a relational playspace to explore the extended site as well as the theoretical implications of beyond human relationships, or what Barad describes as the 'interconnectedness of all things' (in Cahill, Coffey, \& Smith, 2016, p. 80). Movement, and its expression through the art of dance, 'is an embodied practice that engages bodies as matter' (Barrett and Bolt as cited in Ulmer, 2015, p. 39). The body has limitations within itself and inspires both matter and movement to play within the imaginary boundaries. A body enables and disables depending on the constraints of relation, and the creativity happens in the spaces between, stretching the material availability to explore and investigate the potentialities of the body as a conduit for relationships of matter to itself. Cognizant of the new materialists theoretical positioning, it is plausible that the 'body becomes an ontological site of being' (Ulmer, 2015, p. 38). The aim of the excursion is to employ and deploy choreographic practices to account, analyse and create movement and appreciate the embodiment of matter's limitations through self-relation.

The provocation is simple. Movers are invited to develop a spatial limitation in the sand, to draw the outline of an identified space or 'corridor' using only their feet. The design needs to be drawn within ten seconds and reflect some thought about the beach on which they create. The movers are also instructed to configure a movement pattern, which needs to be repeated twice in order to commit the movement to bodily memory while deepening and intensifying the markings more with each iteration. Ironically it is the absence of thought that is an indicator that body memory is enacted and that a reliance emerges on the bodily experience to provide knowledge, build awareness of capacities and dispositions, and to structure and guide through movement (Koch, Caldwell, \& Fuchs, 2013). The movers are then asked to find unexplored spaces away from their canvas and visualise imaginarily themselves creating the lines. They recreate smaller memories of the drawing on the sand.

The movement is fleeting and the capture elusive.
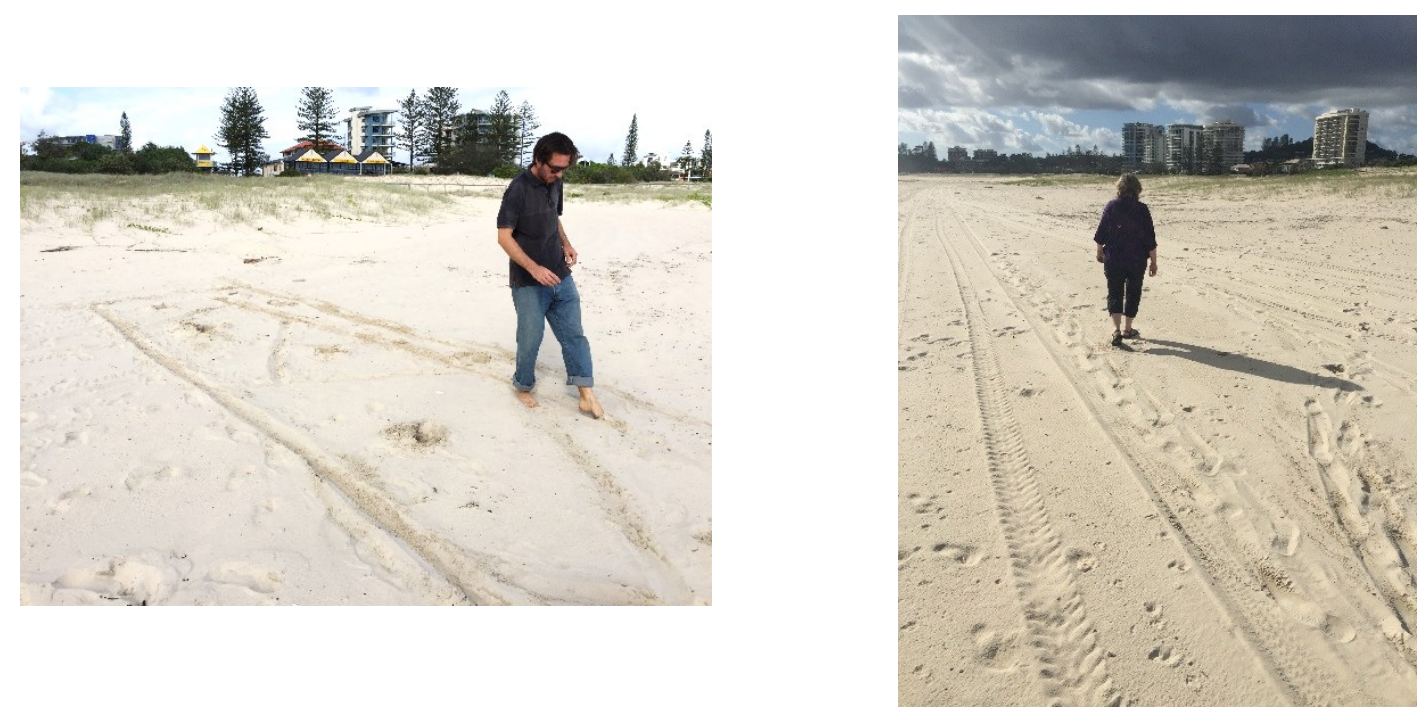
The beach as a site emerges from fluidity with boundless limitations. There is a presence of lines, imposed, imagined, observed and disregarded. The purpose of controlling flow seems at odds to the reality being explored $a / r /$ tographically, and yet the constraint of the task is the very impetus for movement.

The movers play.

Movement is the central focus and as movers we imagine and create. The beach provides an open surface for gesture and inscription, while also activating a geographic spatialisation of education outside of institutional boundaries. As a kind of autonomous zone or deterritorialised space, the coastal landscape becomes the cloth from which a choreographic space-time can be cut. This becomes our task: to craft a block of space-time as the corridor for a choreographic experience.

What emerges from the process of diagramming the enactment of corridors in our experimentation is the relationship between a choreographic impetus (or the will to move), the enabling constraints of the spatio-temporal proposition, and the emergence of a series of structured improvisations that produce difference through bodily repetition.

The movers immerse themselves in the sand. For moments the sand and their skin become one and it seems difficult to know where one started and the other ended. The movement has a linear legacy, a suggestion of a corridor embodying inside and outside of the constructed perimeters. The design is made obvious through the indent in the sand, yet the movement suggests that the lines extend upward into the air creating corridors. The base of the space is evident and implied as it permeates the air with suggestion. The movers' respect their imaginary walls, deliberately working within or without the corridor, suspending (dis)belief, reminiscent of days when a childhood thought allowed for potentialities only barely grasped.

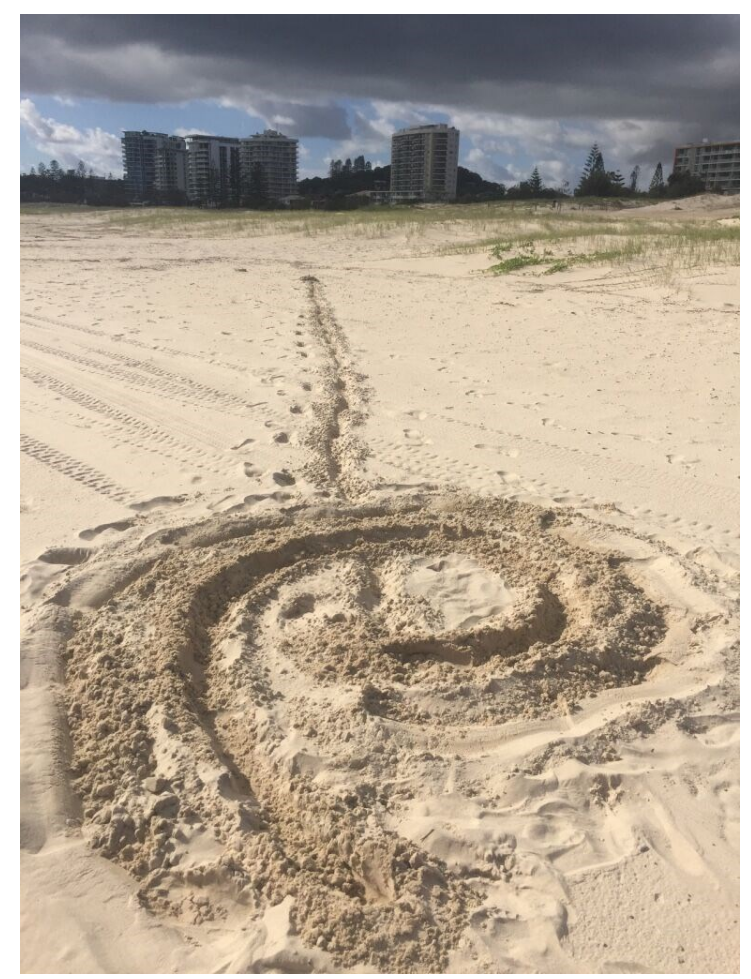

The product of the practice was artefact/ relationship/ teaching moment. The contributions of the audience, the dancer, the sand, the imaginary corridors, and the potentials of pedagogy for all, make for a fertile investment of affect. The accessibility of the sand both geographic and material afforded ample opportunities, and could be adapted and adopted into any learning site irrespective of age.

In the dance world, 'corridor' is a choreographic term used to describe spatial constraints that are designed to enable 'structured improvisation'. Corridors are commonly used to break up the studio or 
stage space into blocks within a larger floor pattern, allowing choreographers and dancers to enact improvisational movement designs within a complex spatio-temporal structure. The corridor on the sand gave a start to an a/r/tographic field day; with limited instructions the bodies drew, or perhaps just moved. In creating the corridor the responses varied in size and shape; and in directions against the backdrop of the foreshore. One forward, one sideways and one on the diagonal: the experience becoming the borders, and the borders becoming the canvas. The corridors were complex, simple and yet multi-dimensional, stretching the possibilities of what a corridor could be and what it could house. The movers performed with rhythm and dynamics and manipulated the sand for effect, and the sand pushed back. The movers' focus became intensive and intimate and entwined: with the activity, with the lines, with the sand and with their imagination. One mover reflected afterwards that she was "struck by the intensity of our engagement -concentrating on mark making in the sand. We were in relationship with this corridor of sand - this stage-like place where we performed to the sea itself."

These relationships, as elements of movement, are concerned with the interactions between the body and itself; the body and other bodies; the body and the objects it can grasp; the body and the environment it co-inhabits with myriad others. Whilst this event was stimulated by spatial exploration, the trace elements of the activity were the residue and accretion of these material relationships. We can see evidence that the body behaves differently when objects and environments are introduced and considered as part of movement, and bodily responses are altered and augmented in response to

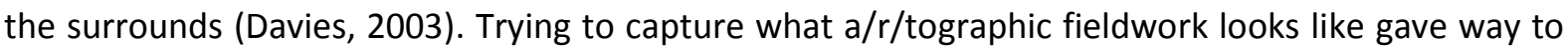
what it feels like. As Ulmer (2015) states:

What new materialism offers to dance-based practice-as-research, therefore, is an emphasis upon dancers as knowing beings within dynamic systems of movement. By sharpening the focus on dancers as embodied beings, new materialism offers an additional approach for embodied methodologies. (p. 39)

As $a / r /$ tographic fieldwork would encourage, the opportunity arises to creatively document understandings of movement and matter as process. The invitation of new materialism to reconfigure movement foregrounds the materiality of text, imagination, and poetics as the concrescence of bodily experience. The dance of writing also moves with the rhythm, with space, dimensionality and the sharing of meaning as public intimacy.

We are invested in movement,

And that it is matter.

And it matters.

And the matter is movement, And that matter moves, is moved and is moving.

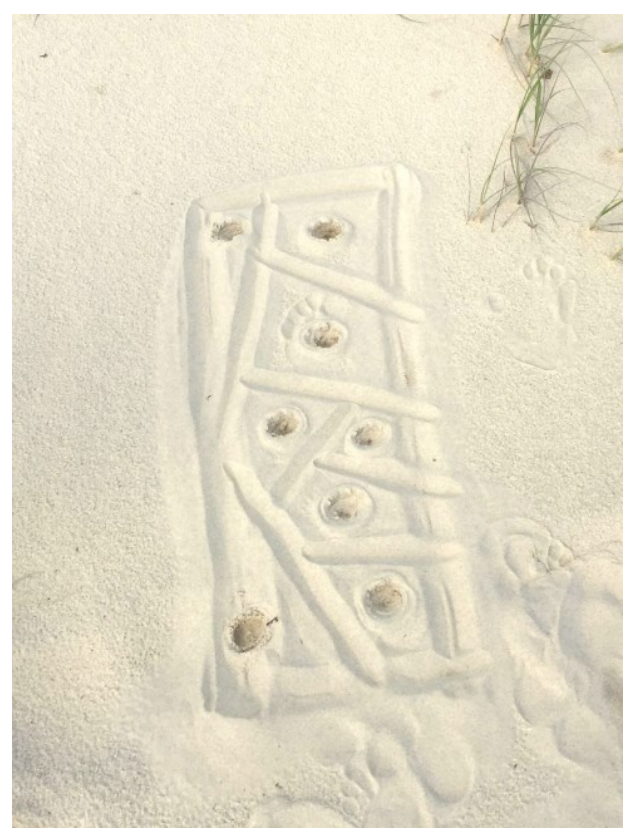




\section{Flight}

As we step off the beach and back onto the esplanade running parallel to the ocean, we transition into the next experiment with how movement comes to matter as we consider lines of flight as advanced by Deleuze and Guattari (1987). We stand in a circle and share single words associated with the concept of flight: the emphasis being on the materiality of the words rather than their syntactic properties. It's a simple algorithmic design in which each word spoken provokes the next, each word taking on some liminal, subconscious relation with the previous. There is a speed involved, a movement circling at the speed of thought - the very notion of words as transcorporeal entities (Alaimo, 2010), passing through the bodies that make up a pack or collective, weaving thoughts together. This is indeed flight, a way of putting the concept to flight in ways that change the consistency of the concept itself: how flight can be thought.

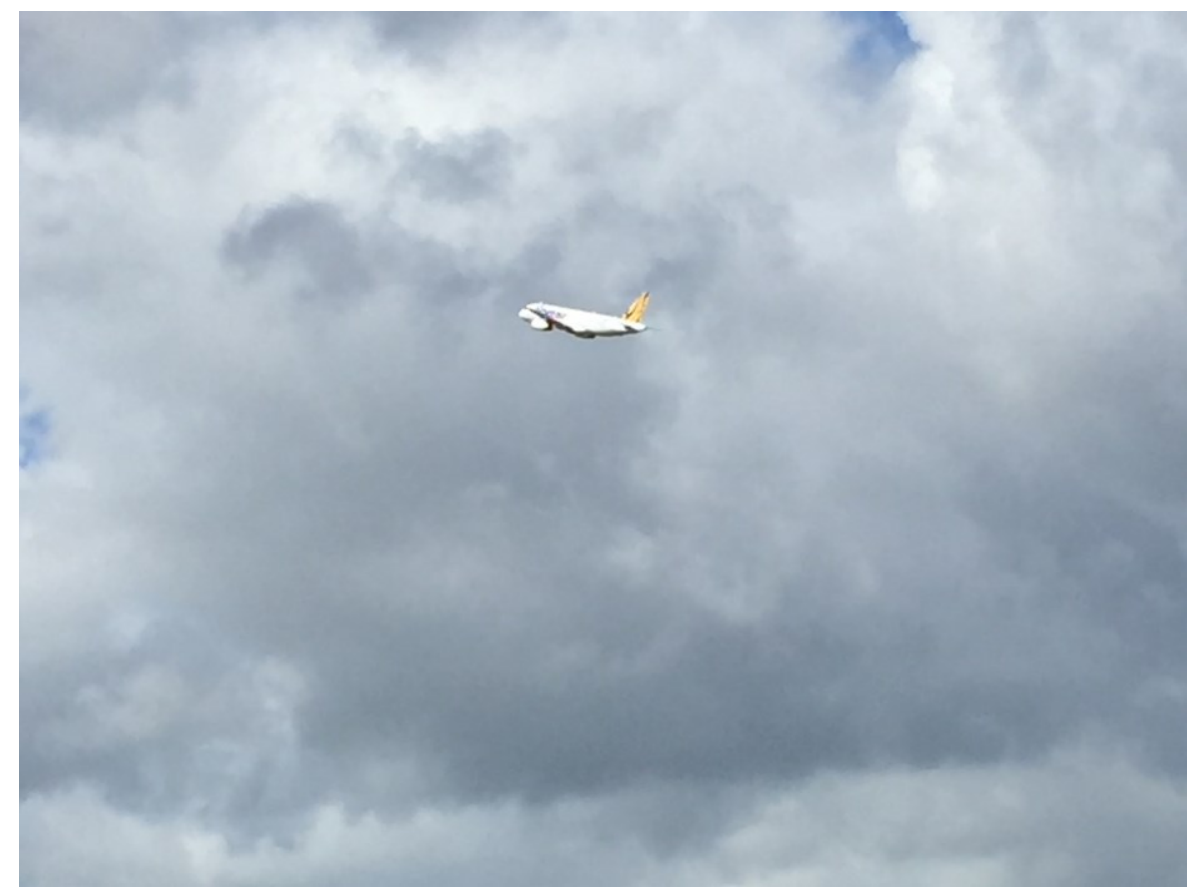

A six word memoir: In-between- Invisible lines of flight

We break the huddle and get into our cars and drive to an area of the airport that is lined by security fences and signs to keep out, a strange kind of borderlands in between the university and the actual runway. Curiously, the campus borders intersect two side-by-side federal states and amidst these visible/invisible borders, an international airport stretches across large swatches of land. Two time zones playfully engage with habits of mind and while no signs dedicated the land to Indigenous peoples, we remain aware of the contested ownership and colonization of the land. As we take all of this into account, we walk the terrain considering a proposition inviting us to experience borders in relation to flight. As Deleuze and Guattari (1987) state:

Lodge yourself on a stratum, experiment with the opportunities it offers, find an advantageous place on it, find potential movements of deterritorialization, possible lines of flight, experience them, produce flow conjunctions here and there, try out continuums of intensities segment by segment, have a small plot of new land at all times. (...) Connect, conjugate, continue: a whole "diagram" as opposed to still signifying and subjective programs. (p. 161) 
Together we walk though these disjunctive borders and time zones, peering into and beyond the secured borders and the invisible borders. We write six word memoires, take photos, and linger within interpenetrating territories of conflicting agency. Our bodies constantly navigate the open and closed spaces as we move, experimenting with our own lines of flight as flights soared above and beyond. We feel an entanglement of experiences emerging. Using Karen Barad's (2007) concept of intra-action we come to appreciate how each person's study within the space influenced our own. Rather than doing this work on our own and experimenting with self-initiated ideas, working together in relation to one another, in a completely emergent space, brings forward multiple lines of flight that pursue diverse directions, points of view, and purposes, creating an assemblage of diagrams. Indeed more potential emerged together than if we were apart.

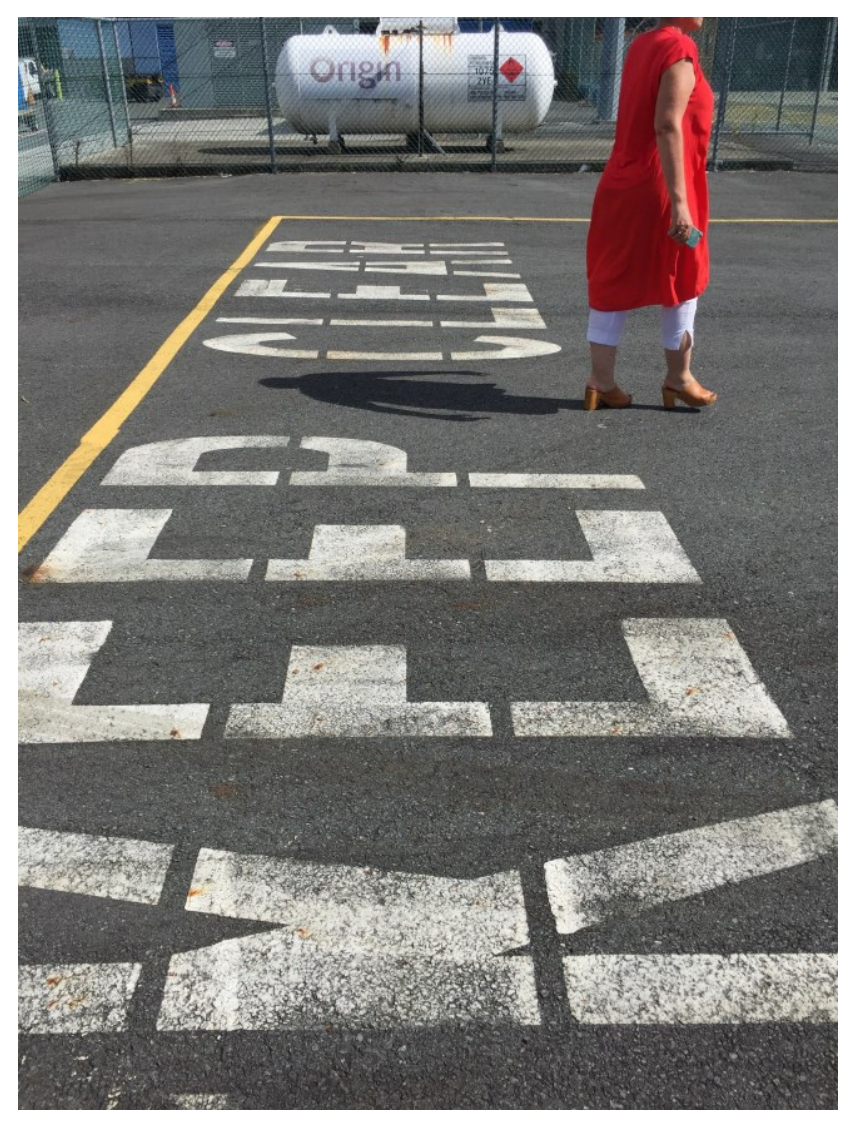

Six word memoir: Origins are coming, move away now

It is here that our 'work' of art exists - in the spaces where nothing yet everything exists. We accepted the ascribed borders and escaped them to imagine the places and spaces as open to potential. Deleuze (1994) would say: 'The work of art leaves the domain of representation in order to become "experience"' (p.56). As our collaborative $a / r /$ tographic fieldwork experience focussed on the potential of flight, we encountered movement as a choreographic architecting of experience. It was through our diversity that we experienced the potential of how environmental arts pedagogies might respond to a changing world. By creating an assemblage of lines of flight intersecting, eclipsing, falling into, rising from, and entangling one another. We experienced how movement comes to matter. 


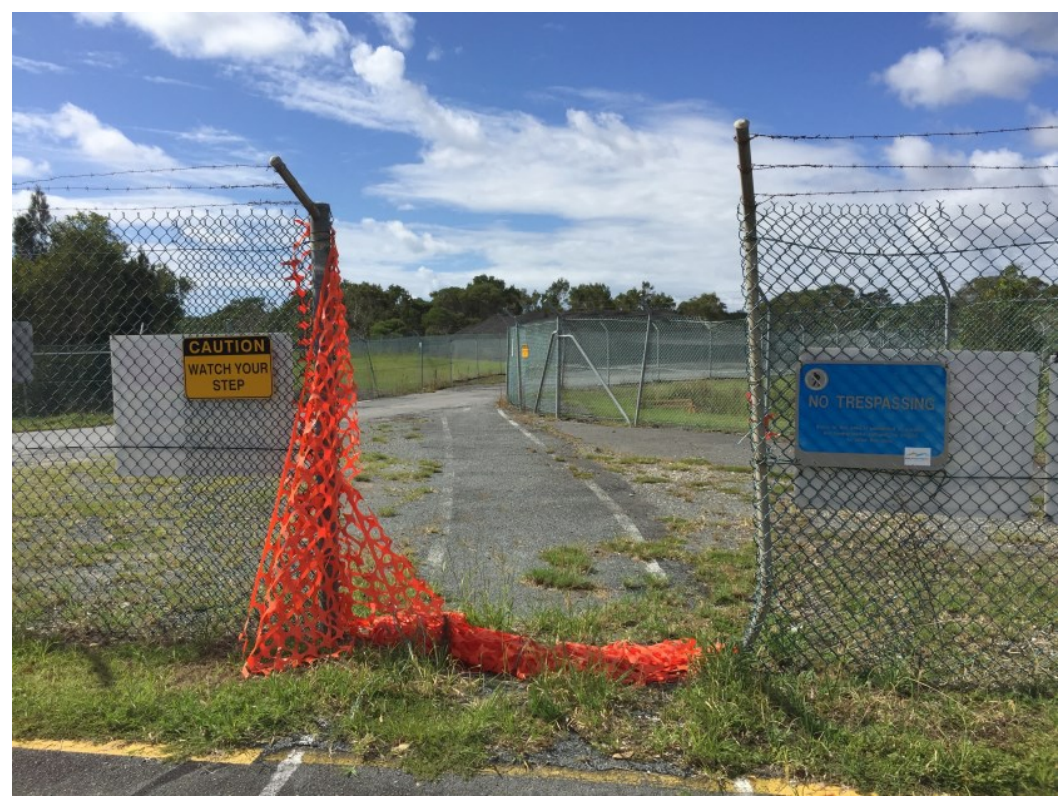

Six word memoir: Borders collapsing remain intimidating, nature reigns

Deleuze's project of immanent ethics asks us to consider how we should live in the world. In this sense, ethics is always about becoming: that endless state of change that moves us into unexpected encounters. After all, becoming is always in the middle. A middle space is in constant movement as all entities vibrate in connection to all other entities. Becoming is therefore not about moving toward transcendent values; instead, we embrace life's immanent ethics (Deleuze, 2007) and pursue our desires through experimentation with ideas. Environmental arts pedagogies that embrace these middle spaces are moving us toward an experimental, personal, societal and ecological emergence where movement matters in our immanent becoming.

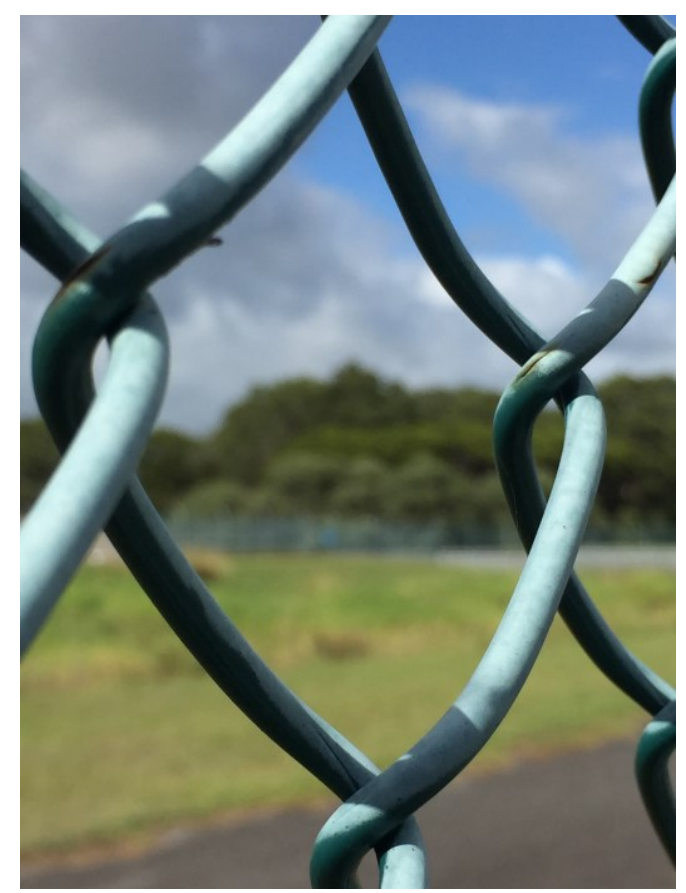

Six word memoir: Pulled to the limit we expand 


\section{Viscosity}

We reassemble from our forays into the borderlands between territories, walking together into the university campus proper and taking the elevator up to the tenth floor. Suspended in the glasspanelled staircase that flanks the building's northeast corner, we find a peculiar assemblage of found objects and media for exploring the concept of viscosity through material experimentation. There are two upended wooden boxes, between which is suspended a ribbed sheet of toughened glass taken from the front of an old oven. A range of found art materials are arranged on either side, including variously coloured inks, solvents, binders, varnishes, and fluxes, along with a bucket of ice cubes. A high-resolution camera is placed in the space underneath the sheet of glass, allowing the movements of bodies and materials to be captured from the lower surface. It's a cross between an interactive artwork and a science experiment: what Barad (2007) might call an apparatus of material production.

\section{Viscosity}

1: the quality or state of being viscous

2: the property of resistance to flow in a fluid or semifluid

3: the ratio of the tangential frictional force per unit area to the velocity gradient perpendicular to the direction of flow of a liquid -called also coefficient of viscosity (Merriam-Webster, 2016)

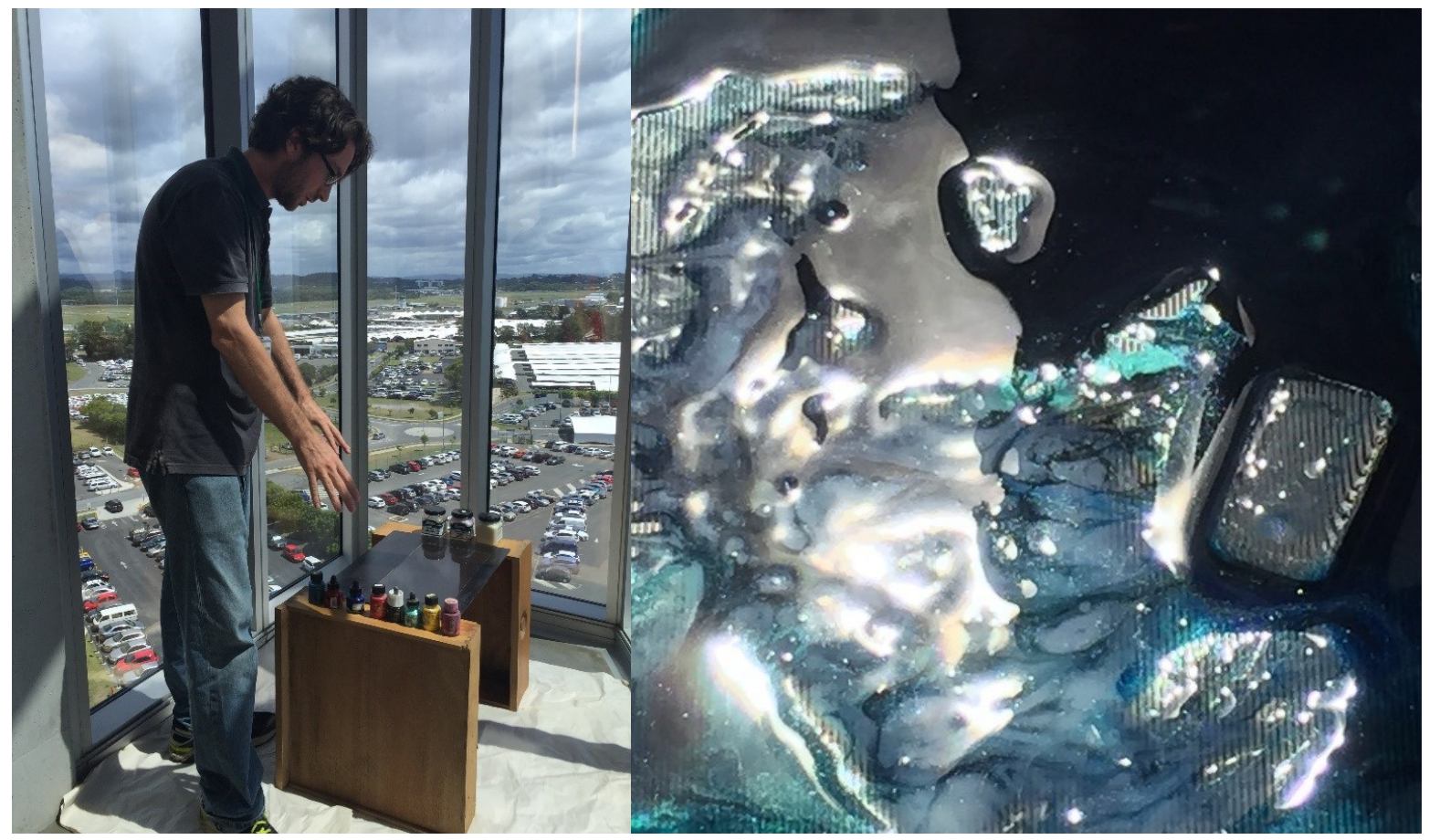

Viscosity is not only a property of fluid materials, but is theoretically a property of matter in all possible states, whether liquid, solid or gas. There is even scientific evidence of viscous movement observed over long periods of time in concrete formations such as granite (e.g. Kumagai, Sasajima, \& Ito, 1978). Attending to viscosity reveals that everything that exists materially is also in movement, but that these matter-flows have varying speeds, consistencies, and coefficients of resistance and mutability. Even the elemental material flows of air, light and water vapour exhibit viscous resistance in relation to other materials and fluctuations in temperature. For instance, flight only becomes possible through 
the dynamic resistance between air and water vapour ratios and higher viscosity materials that make up the wings of birds or airplanes.

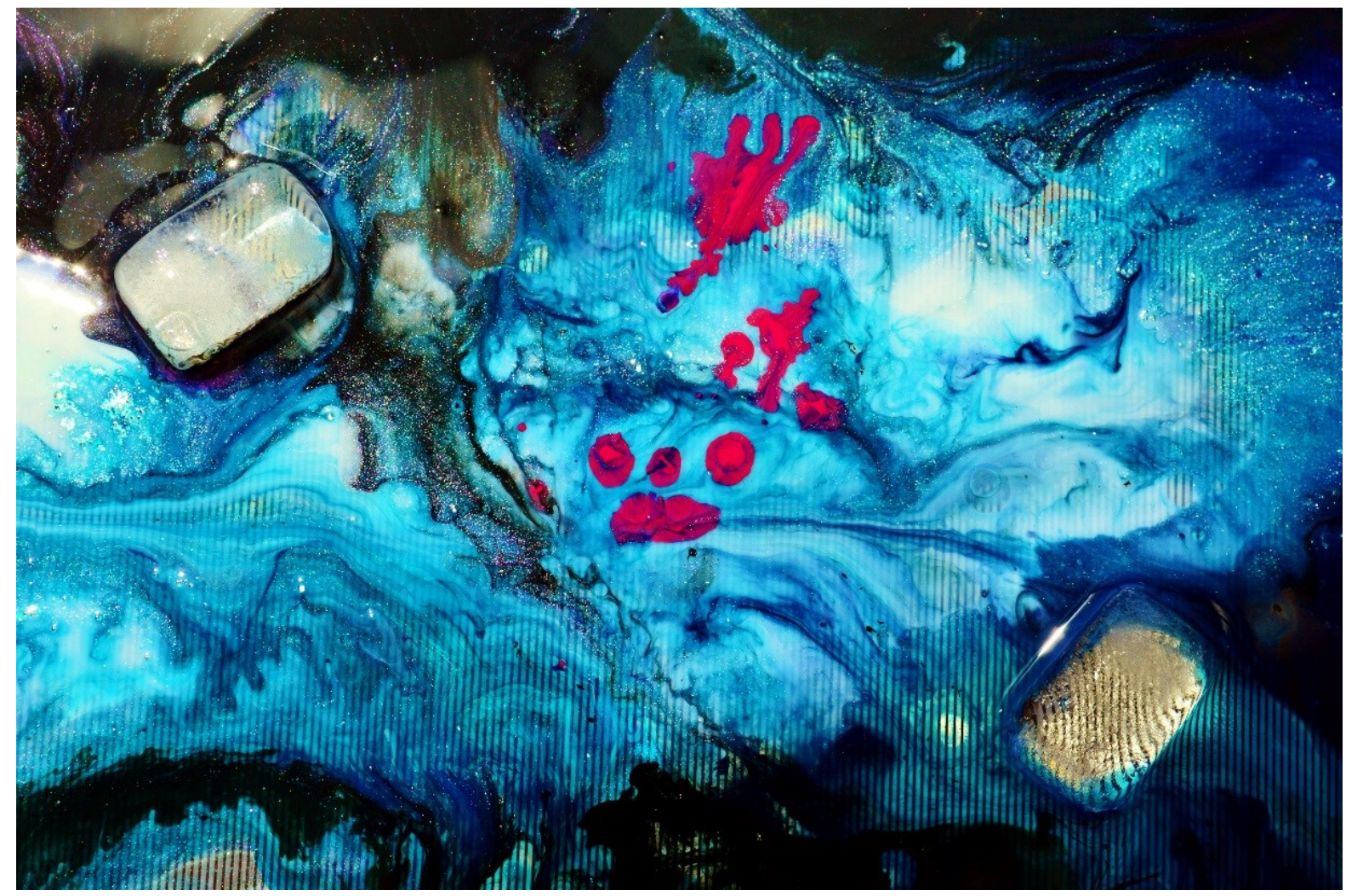

Situated in the corner of the 9th floor stairwell overlooking the university parking lot and the Gold Coast's highways and beaches, we begin to realize that the glass structures joined with steel and granite continue to move at ever so slight and miniscule speeds. We begin to squeeze, flick, squirt, and layer the materials onto the surface of the glass, probing and guiding mixtures of varying viscosities into differntial patterns of colour, light, movement, texture, and form. As we drop the ice cubes into the mix they immediately begin to change from solid to liquid, gliding on their own volition across the surface while releasing water molecules into the concentration gradient of the materials. Never does the paint become muddy - it upholds its consistency, discerned as a mixing of colours that somehow retain their origins. The surface is dappled with moving patterns of coloured sunlight and shadow.

Viscosity is a feature of the way in which time emanates from objects, rather than being a continuum in which they float. (Morton, 2013, p. 35)

The surrounding social and ecological environment becomes part of this molecular experiment: the stairway surrounded by glass in every direction, light flooding in from multiple sources, the panoramic tableaux of ocean, roadways, airport and parklands. We begin to notice the numerous viscosities operating within this vista. The viscosity of a flock of birds in flight, the viscous flows of human and nonhuman capital across the surfaces of the landscape, the burning of fossil fuels with each car that drives by, or plane that takes off. The concept of viscosity takes on a new consistency, as we raise questions regarding the viscosity of thought and bodies in movement, the flows of desire, engagement, and creativity in classrooms, as well as the distributed viscosities of social networks, economic capital, and political ecologies. 


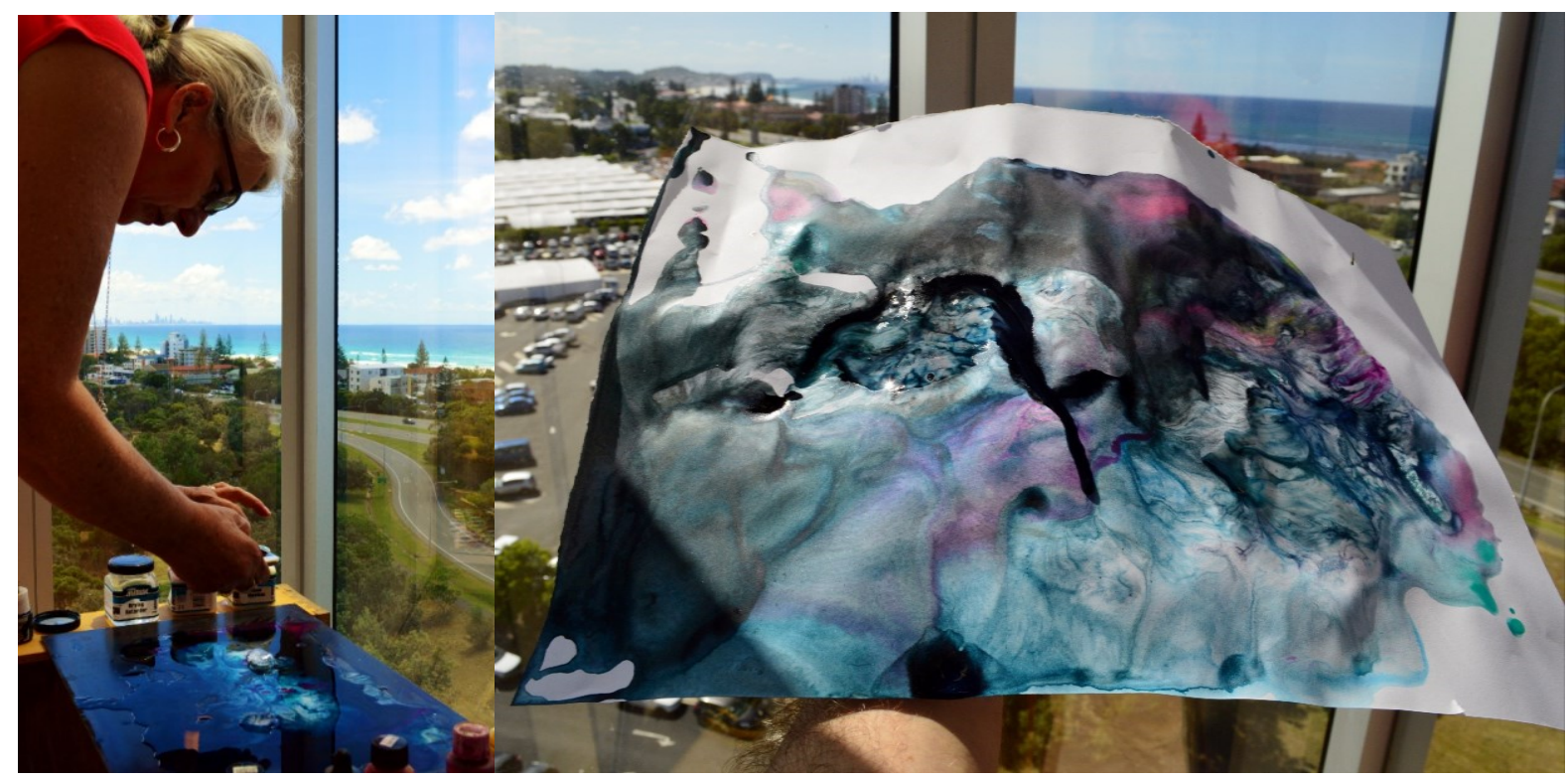

Viscosity wants to emphasise this mobile spatiality of togetherness, of coordinated flowing and relative stability ... Human flows become viscous in crowds, in large airports and in traffic jams. ... packs, cities, nation-states, social classes and racial formations are also examples of human viscosity. (Saldhana, 2008, p. 329)

As a concept for environmental arts pedagogy, viscosity enables us to account for the primacy of movement in materiality itself, the way that movement puts bodies into motion and thoughts into flight (Manning, 2013). We can begin to consider learning itself as a viscous material flow of transcorporeal movements that pass through, activate, and re-arrange the capacities of bodies (Alaimo, 2010; Tuana, 2008). The viscosities of light passing through a classroom window; the increased metabolisms of children when they go outside to play; the shifts in temperature, air pressure, and humidity that alter the flows of bodies; the viscosities of affect in the compositions of porous social bodies: the inclusions and exclusions, engagements and disengagements, mixtures, dilutions, diffusions, permeations, precipitants and calcifications of experience.

\section{Construction}

In returning to the office level, we regroup, astonished to near-silence by the aesthetic positionings of our actions and our thoughts and our documents of these movements and these matters. All at once we begin to speak eagerly as our thoughts follow our actions, jumbling and tumbling in excited dialogue. Reluctantly we restrain and constrain; we have yet another concept to interrogate and further work to explore. We drift into the next episode and bring ourselves back to the quiet, to the flow (Csikszentmihalyi, 1997).

The hushed space of intensive artmaking is contrasted with the noisy space of construction next door. The campus we inhabit is growing, expanding and developing around our very bodies, as another building is added to our footprint. Once a lovely green space of swamplands, of small animals and native flora, it has been excavated and repurposed in order to accommodate a further wave of student occupation and learnings, growings and doings. We have watched, from the end of our corridor, as the space beyond us is transformed: once a place to rest our eyes, now a place to avert and anticipate. The ground has been cleared, and a machinic assemblage (Deleuze \& Guattari, 1997) of human and 
non-human agents is working vigorously to construct our next building. Its monstrous presence in our working day is one of imminent capture. The place of construction today is not the same, as yesterday and tomorrow again it will be altered further. Issues of encounter, emplacement and displacement, synergies and discords are present and in constant flux in this space, and it is those movements that we now seek to map, somewhat inadequately, as each collides and interrupts and glides with and against the other (Knight, 2016).

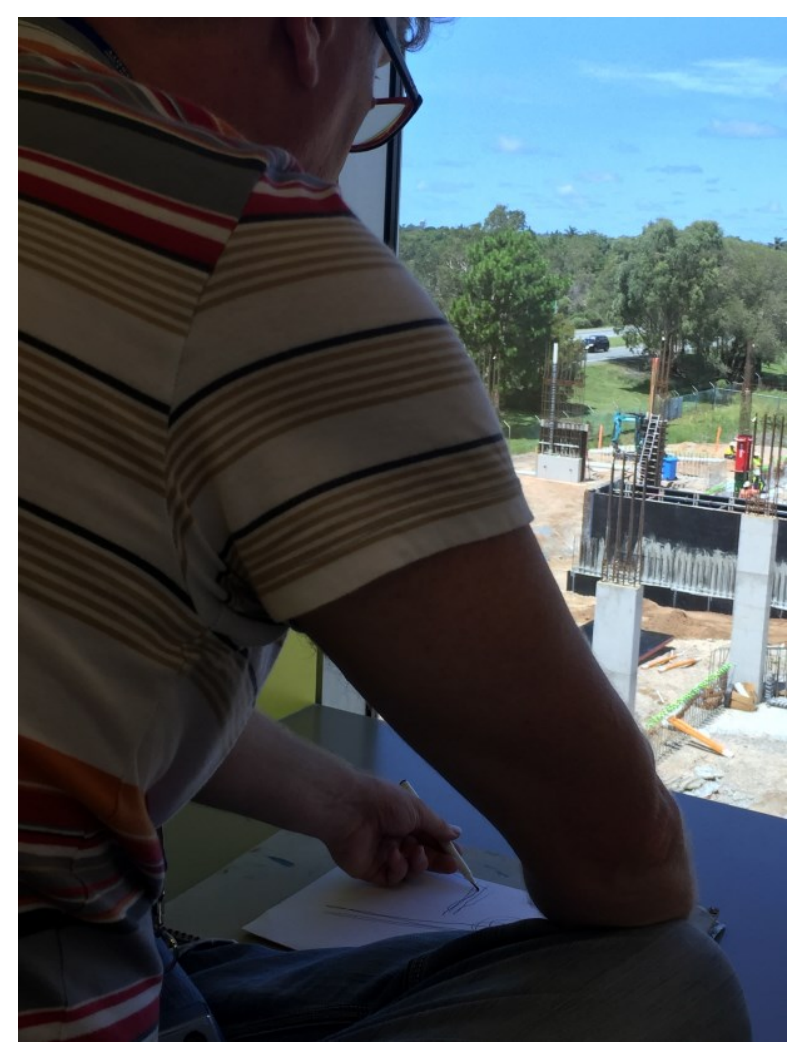

The material process of construction has been a daily reality for those of us who inhabit this campus. It has interrupted, inconvenienced and intruded in our lives. In positioning this last experimentation we call forth Ingold's (2007) work on lines and surfaces, specifically those that track and document movement, such as the passage of feet on the ground, or the movements of tank treads across the landscape. In short, the passages and lines and movements through time and in place, this place, become ecologies of entanglement, a meshwork. As Ingold reminds us,

Indeed nothing can escape the tentacles of the meshwork of habitation as ever-extending lines probe every crack or crevice that might potentially afford growth and movement...for inhabitants, however, the environment does not consist of the surroundings of a bounded place but of a zone in which their several pathways are thoroughly entangled. In this zone of entanglement - this meshwork of interwoven lines - there are no insides or outsides, only openings and ways through. An ecology of life, in short, must be one of threads and traces, not of nodes and connectors....Ecology, in short, is the study of the life of lines. (2007, p. 103)

In this experimentation, we seek to create traces, entanglements, meshworks, as we follow the lines of movement over time and in place, even as that place is itself in constant motion and in mutability. In this instant, and for a comparatively fleeting moment, we follow those lines by engaging the 
technologies of drawing, of making marks, in this case abstract lines, on a recording surface. We find our way through this meshwork of construction, as drawings.

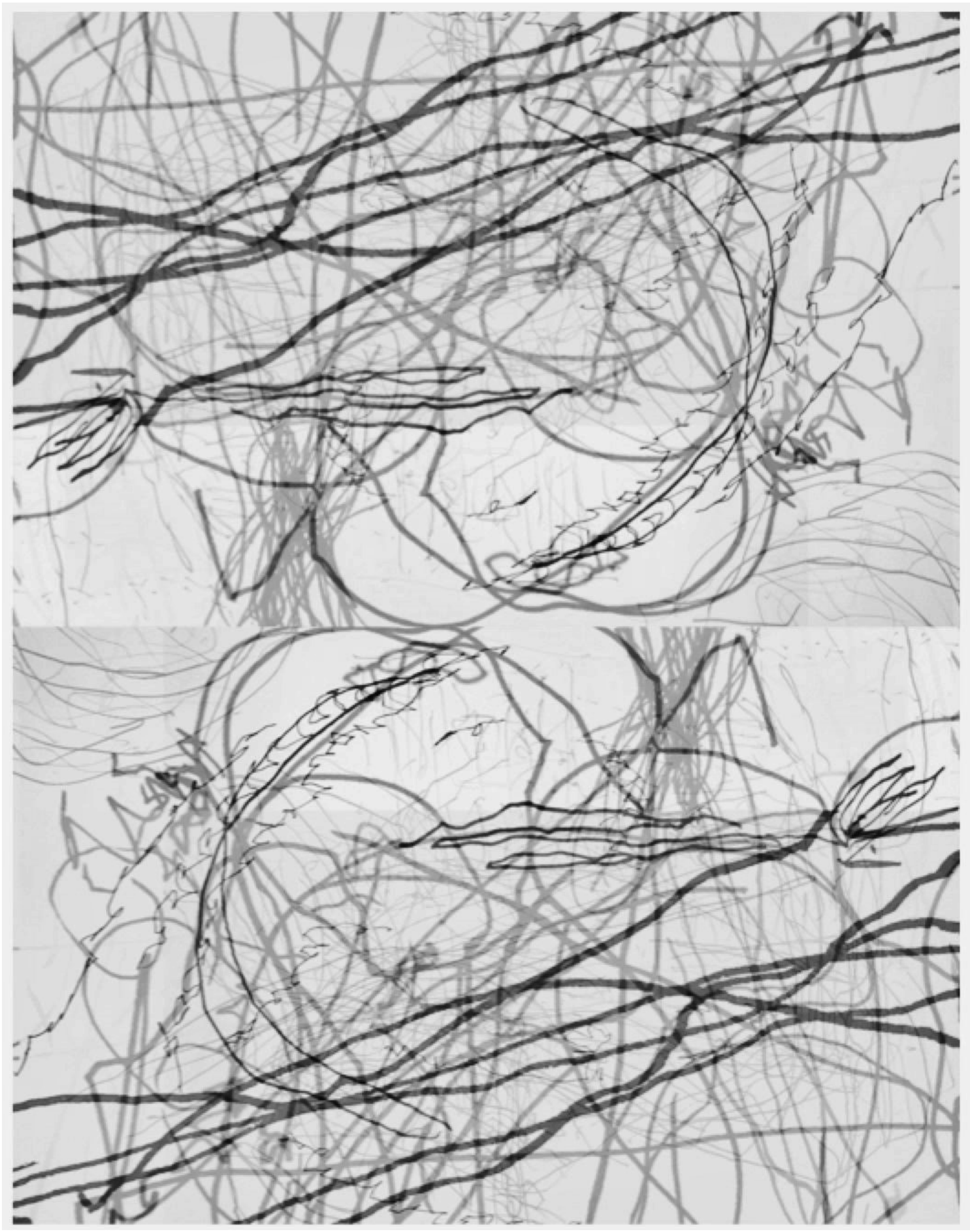

The language form of drawing has been a sense-making device in all of human existence. It precedes written language through history but also through life, as children engage with mark making prior to the development of a coherent writing schema. Drawing also requires a different type of cognition to writing, or speaking, although it is indeed a language form. As we draw, our chatter ceases, and we continue in silence through this engagement with seeing, with following, with way-finding (Lasczik Cutcher \& Irwin, 2017). 
The drawings have been further troubled and extended through the use of layered digital media, so that the images created by the four individual artists have become enmeshed, further entangled, curated as a single artwork that enables the viewer to see in and with. All four drawings have been layered together to robustly portray the suite of marks: the energies of the construction site, the movement of feet, tires, feet, tank treads, wheels and feet that were followed and mapped. The drawings become a layered document that constructs construction, a network of aesthetic engagements, a c/a/r/tography (Lasczik Cutcher \& Irwin, 2017; Rousell \& Cutcher, 2014). Thus, the artwork both describes and embodies these situated $c / a / r /$ tographic events, becoming itself a curated display of sensory encounters with construction and its evidentiary passages.

\section{Diagramming Pedagogical Propositions}

In taking a new materialist approach to $\mathrm{a} / \mathrm{r} /$ tographic fieldwork, the four renderings above have put concepts of movement to work through artistic and pedagogical experimentations with bodies, places, times, events, and materials. In order to further analyse the potentials for these renderings to inform an environmental arts pedagogy, we now undertake a process of diagramming the pedagogical forces and movements at play in each of the experimental situations described above. Diagramming has previously been used as an analytic process in new materialist educational research, including the diagramming of classrooms as topological assemblages (de Freitas, 2012), social practice artworks in schools (Springgay \& Zaliwska, 2015), and the movement of concepts through arts-based research (Rousell, 2017). As Deleuze and Guattari (1987) write, such diagrammatic processes 'do not function to represent, even something real, but rather [construct] a real that is yet to come, a new type of reality' (p. 142). Accordingly, the diagrammatic processes we undertake differ from conventional understandings of diagrams as visual or textual representations or mimetic descriptions of pre-existing processes. The diagram is instead associated with mapping the pedagogical potentials of each rendering as an abstract machine that produces new movements of thought. In this way, diagramming necessarily involves analytic techniques that operate at the very limits of thought, as a speculative process of analysis that is always opening onto the next threshold of thinking and practical action. As Watson (2009, p. 12, emphasis in original) writes, such 'diagrams do not represent thought; rather, they generate thought'. As heuristic devices for generating pedagogical thinking and action, the diagrams below aim to mobilise the forces at play in the concepts of corridors, flight, viscosity, and construction as they emerged through $\mathrm{a} / \mathrm{r} /$ tographic fieldwork. In this way, we use the diagrams to convert the concepts themselves into methods for generating pedagogical designs that implicate matter in movement, and movement in matter.

Diagram 1: In which the concept of Corridors produces the enabling constraints for the structured improvisation of movement

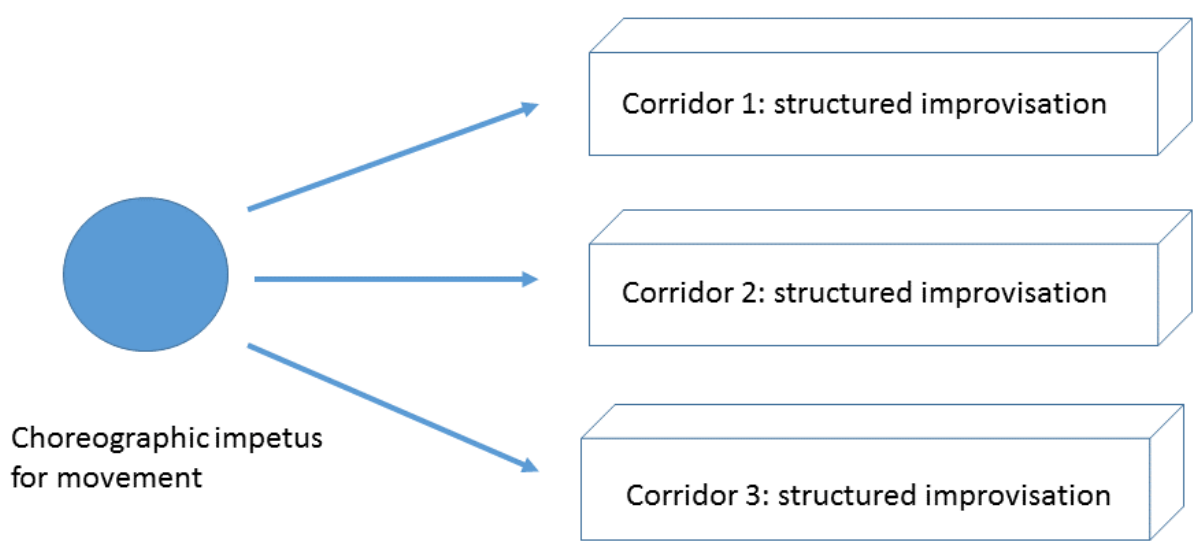


Diagram 1 shows how the concept of the 'corridor' operates as an enabling constraint for the production of improvisational movement within a series of open structures. The choreographic impetus for movement is seen to come from a source external to the corridor, and this could be attributed to the ideas, techniques, affects, and propositions for movement that are embedded in the formulation of a pedagogical design. In this case, the design is based on applying the constraints of repetition in order to produce difference, such that each corridor renders a unique configuration of gestures and patterns in response to a proposition for movement held in common. Rather than functioning as a container or backdrop for human experience, each corridor is actively constructed through embodied practices that mutually implicate space, time, and materiality. Crucial to this formulation is the embodied activation of the corridor as a space for intensive, experimental processes of individuation. From there, the question is how this concept of 'corridor' might come to matter in educational contexts, particularly in terms of how we think about and construct learning environments across a wide range of disciplines and learning areas. We might, for instance, re-think the design of a primary or early childhood classroom in terms of experiential corridors for structured improvisation and movement, rather than pre-fabricated 'spaces' for sedentary forms of reading, art, science, and mathematics instruction.

Diagram 2: In which the concept of Flight moves from a cyclical to a distributed formation as bodies shift from wordplay into photoplay

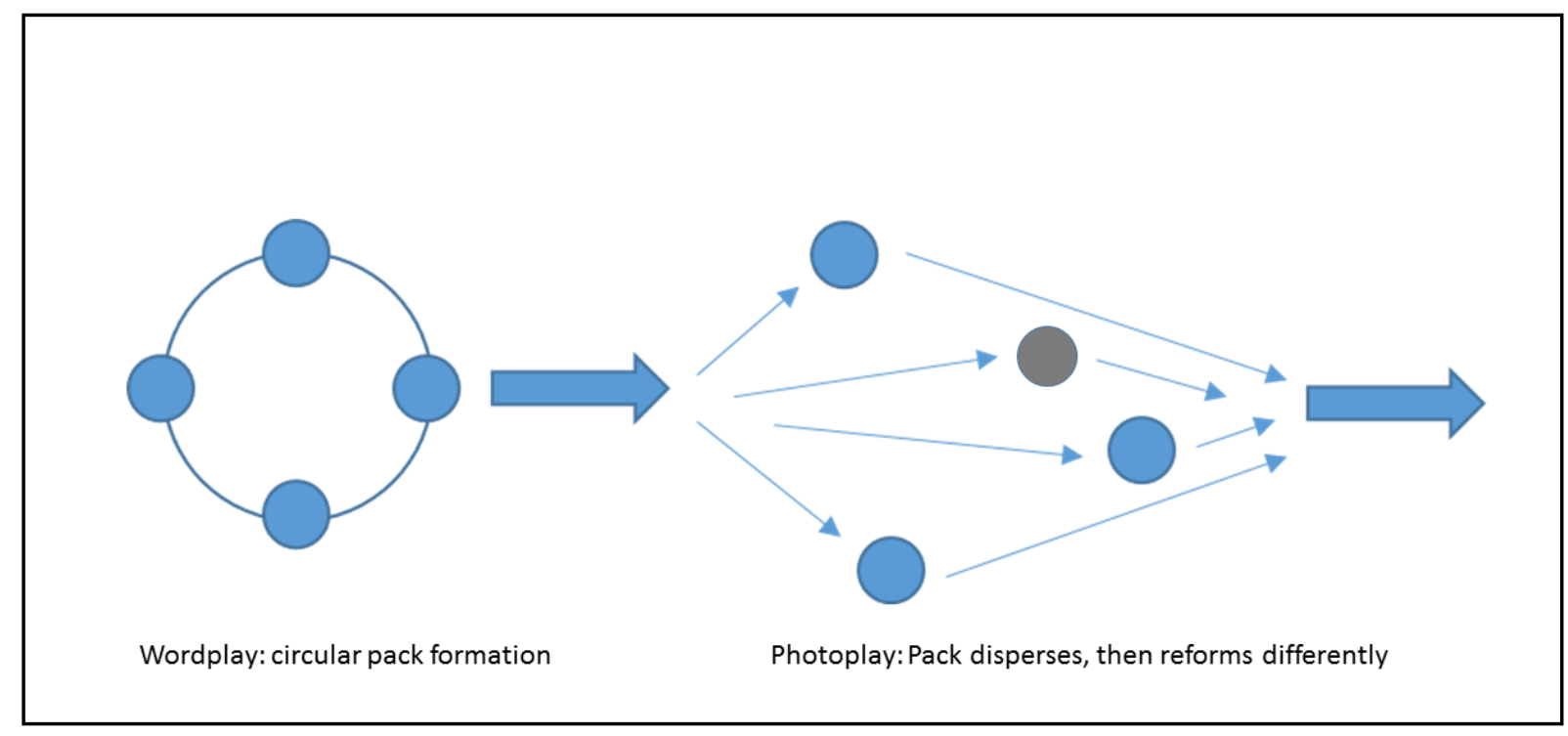

Diagram 2 follows the formations and distribution of bodies as the concept of Flight shifts from a semiotic to a visual register. The two-stage nature of the pedagogical design reveals the differences produced between different arrangements of bodies in relation to patterns of movement. In the first instance, there is a circular arrangement of bodies that facilitates the rhythmic movement of wordplay and symbolic associations with 'flight' within a collective huddle or pack formation. This generated a feeling of togetherness amongst the $a / r /$ tographers, while at the same time generating a semiotic movement of thought across bodies in a unified group. In the second instance, there is a dispersal of individual bodies moving separately and yet together through the environment, with the shared aim of capturing photographs. The distributed movement of the group then contracts once again, back to the circular formation of discussion and consolidation of the collective experience. What becomes palpable through this diagram is the way that the collective assemblage of bodies holds together while passing from one state and configuration of movement into the next. Each stage of the process 
appears to resonate through the next, modulating the learning process without direct intervention or didactic instruction. In applying this pedagogical diagram to the classroom, we can conceive of similar processes that could modulate the degrees of collectivity and autonomy in children's 'flight' through different activities and arrangements of bodies. The setting of circular patterns of movement, thought, and association could be used as the starting point for more dispersed and distributed explorations of ideas and environments, which then lead back to group discussion and the collective consolidation of diverse experiences.

Diagram 3: In which the concept of Viscosity follows the movement of matter across different forms, states, and consistencies.

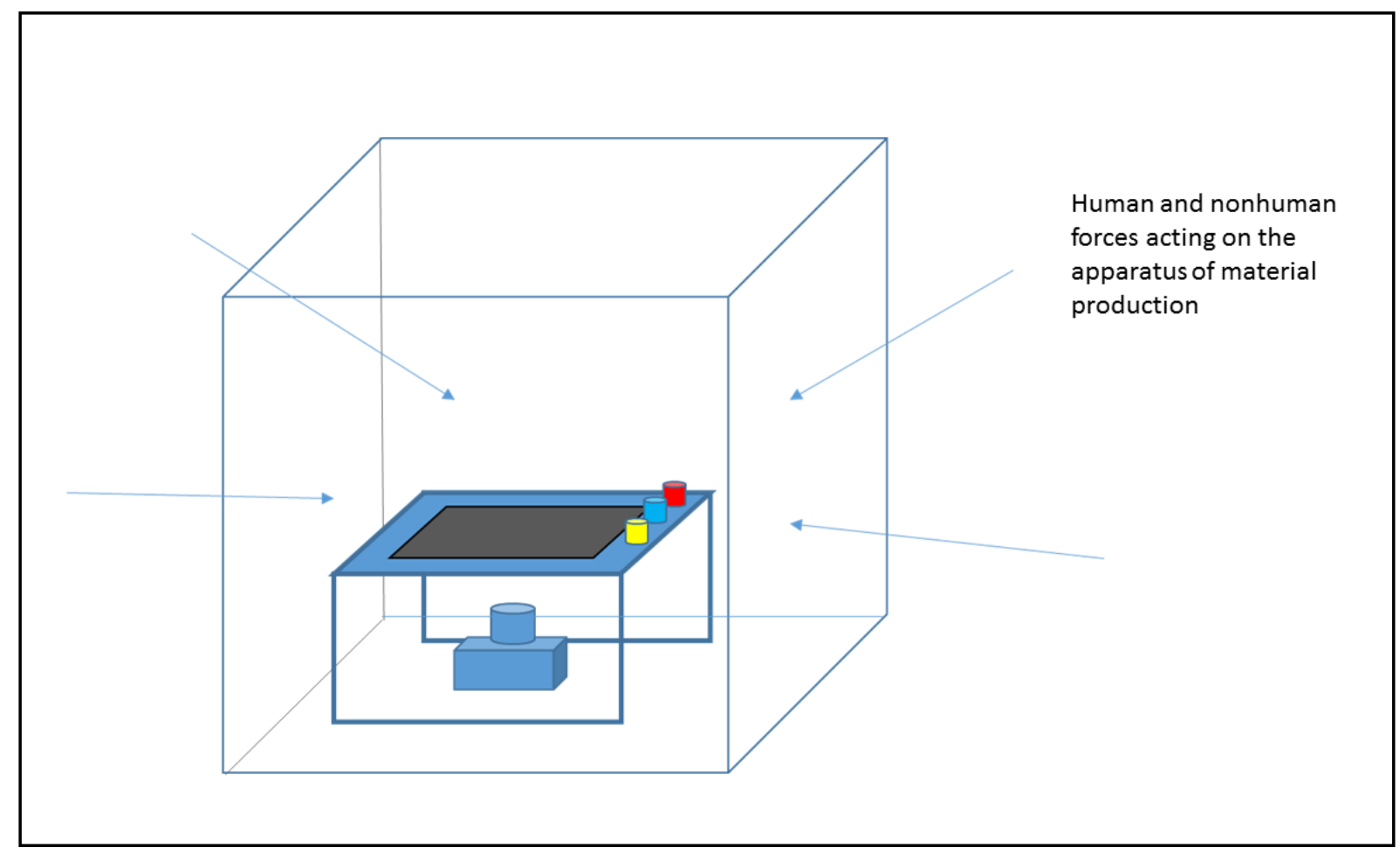

In Diagram 3 we see the pedagogical design of a material apparatus for experimenting with different viscosities of movement and flux. Differential forces are seen to intervene in the apparatus from the outside, including the forces of human bodies that engage with the apparatus as well as elemental forces, such as light and temperature, that affect the states and consistencies of different materials. The machinic apparatus of the set-up becomes the locus for the bodily activation of potentials for organic and molecular movement within the learning environment. This experimental confluence of forces is captured by a camera as a sensing 'body' or 'device' that registers the patterns of light, shadow, colour, movement, and form as materials with different viscosities come into contact with one another. By bringing participatory art and science together through aesthetic and material experimentation, this pedagogical diagram foregrounds the ways that heterogeneous elements of the learning environment congeal into dynamic, spatiotemporal events. If we extend the applications of this diagram into the classroom, we can imagine learning environments that are designed for children to enter and experiment freely with a wide range of viscous materials that mix, meld, and change state depending on environmental conditions. Capturing these interactions through oblique cameras or other ubiquitous sensing technologies would allow both teachers and learners to view the event from the perspective of the apparatus itself, introducing further opportunities for understanding the material and aesthetic processes at play within the environmental arts classroom. 
Diagram 4: In which the concept of Construction connects the observer, the surface of inscription, the architectural frame, and sources of empirical movement in the external environment.

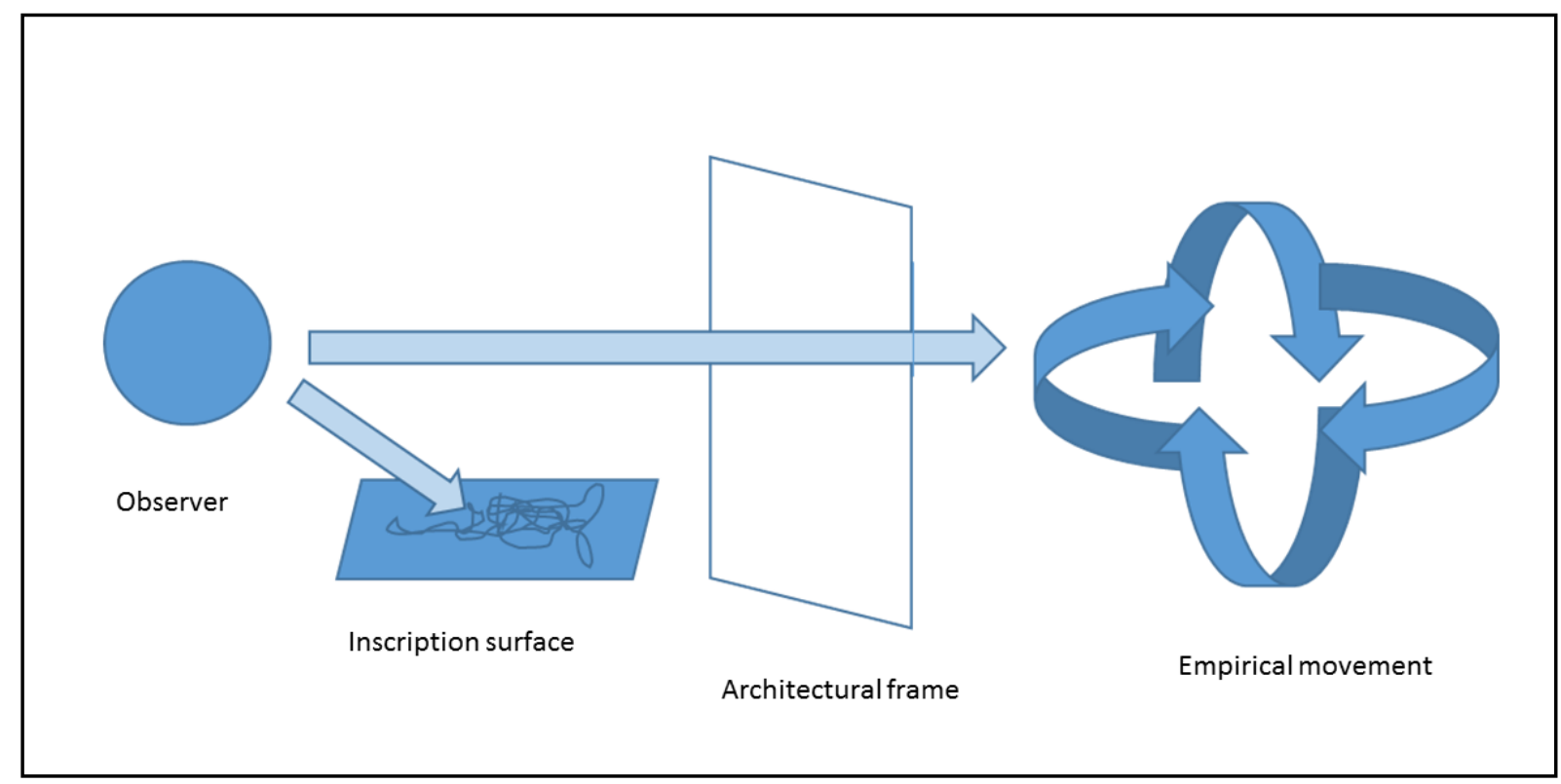

In Diagram 4, we grasp the material processes that enable movement to be translated or 'transduced' through practices of empirical observation and inscription. Drawing is seen to offer a technique for converting movement from one medium to another, feeding the ongoing construction of the external environment through the intensive processes of attunement and creative expression. The observer, in this sense, becomes a conduit for aesthetic expression through movement as it is mediated through architectural framings of the sensible world and the substrates and inscription materials at hand. In converting this diagram into a pedagogical design for the classroom, we can envision children learning to observe and translate environmental movement through various practices of transduction, such as drawing, painting, dance, music, or creative writing. By focusing on the transduction of movement through environmental attunement and responsive observation, children's artistic learning experiences could move from a representational to an enactive, embodied, and embedded mode of aesthetic engagement.

Diagram 5: In which the concepts of Corridor, Flight, Viscosity, and Construction are arranged into an assemblage that produces new concepts, practices, and knowledge applications

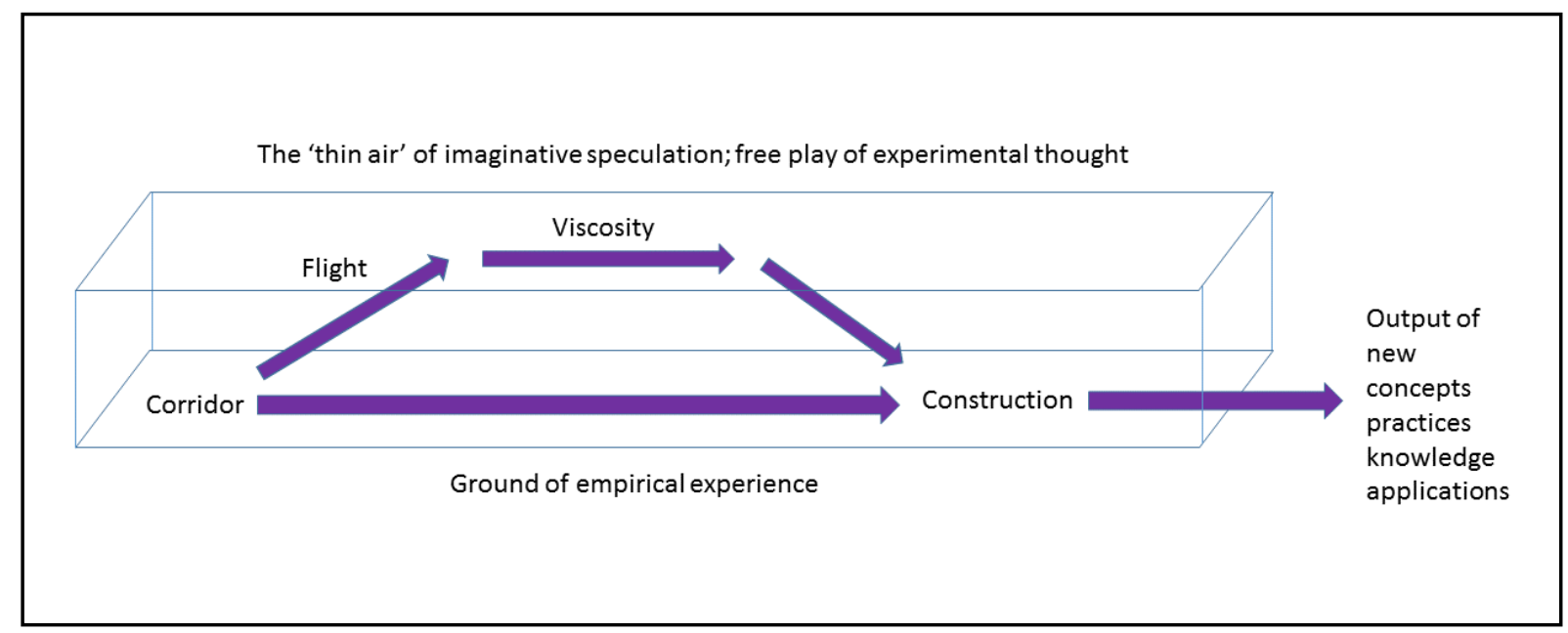


In Diagram 5, we consolidate the previous diagrams within a pedagogical sequence of conceptual experimentations that are linked to Whitehead's (1978) methodology for speculative empiricism. This configuration shows the relationships between the free play of the creative imagination and the embodied materiality of sense experience and rational thought. As Whitehead writes,

The true method of discovery is like the flight of an airplane. It starts from the ground of particular observation; it makes a flight in the thin air of imaginative generalisation; and it again lands for renewed observation rendered acute by rational interpretation ... the success of the imaginative experiment is always to be tested by the applicability of its results beyond the restricted locus from which it originated. (p. 5)

Diagram 5 shows how the concept of the corridor can provide a spatiotemporal architecture for the flight of the imagination; the viscous flows and mixtures of ideas, sensations, bodies, and materials; and the return to constructive observation and interpretation of empirical phenomena. Rather than positioning this sequence as a blueprint or template for environmental arts pedagogies, we see it as a heuristic model for how teachers and children might collectively configure and produce their own learning activities and experiences. In other words, Diagram 5 offers an operative modelling of environmental arts pedagogy as an open-ended and participatory process of learning through artistic and environmental experimentation. Any number of concepts could be substituted for the ones that we have selectively chosen based on our interests in movement and materiality. What is crucial to our pedagogical formulation, however, is the use of the concept itself as a method for empirical experimentations with environmental and aesthetic phenomena. By following the movement of concepts as they modulate and condition material processes, we were able to open up a whole domain of potential learning experiences connecting movement with matter, body with environment, and imagination with empirically-observable phenomena.

\section{Conclusion: Propositions for an Environmental Arts Pedagogy}

In this chapter we have shown how a new materialist approach to $a / r /$ tography can be used to investigate the relations between matter and movement, thus contributed to novel configurations of environmental arts pedagogy. We see the entire process of designing, enacting, analysing, and theorising this project as a modelling of what environmental arts pedagogy might come to look like, and how it might come to work. Drawing together the aesthetic, material, and conceptual yields that have been rendered through this emergent process, we conclude with a series of propositions for those who might adopt a resonant approach to environmental arts pedagogy in other places and times. As we employ the term here, a proposition is a theoretical lure or provocation that combines virtual potentials of the speculative imagination with the empirical dimensions of embodied experience in the actual world. 'Thus propositions grow with the creative advance of the world' (Whitehead, 1978, p. 188). Much like the diagrams in the previous section, the propositions below should be taken as heuristic provocations, vehicles, and catalysts for learning activities and experiences that exceed our capacities to foresee.

\section{First Proposition: Use concepts as methods}

We began with new materialist theories of movement and materiality as the points of departure for this project. From there we each selected a concept as the vehicle for practical experimentation with specific locations, environments, activities, dialogues, materials, media, techniques, and technologies. On the one hand, this approach situates, expresses, and materialises the concept through concrete practices and artful experimentations. On the other hand, the concept retains a consistency 
throughout the experiment that contributes to the pedagogical yield of the process. This lets us learn through concepts as we put them to work creatively within an architecture of engagement, rather than trying to learn about concepts in ways that are detached from worldly experiences and emplaced encounters.

\section{Second Proposition: Modulate the thresholds between individual and collective learning processes}

Our experiments were designed individually, and yet they were enacted, documented, analysed, and theorised collectively. This allowed us to see how the thresholds between individual and collective learning processes could be warped, stretched, conditioned, and modulated in relation to different concepts and practices. We therefore propose that the individual become just another element in the pedagogical machine, a learner amongst learners, a mover amongst movers, an organism amongst organisms, a flow amongst flows.

\section{Third Proposition: Foreground the environmentality of art and pedagogy}

Rather than making art about the environment or environmental issues, we tried to create spaces for thinking and working artfully across environmental scales, durations, and life processes: quantum, molecular, genetic, cellular, organismic, social, ecological, planetary, cosmic. Ultimately we found that waves crashing on the beach, an airplane taking flight, an ice cube moving across a sheet of glass, or machines moving tons of earth and steel all become active and agentic elements of an environmental arts pedagogy - with or without the intentionality of the artist, researcher, or teacher as masterful human identities. This makes the environment itself the medium and milieu through which artful learning process occur, rather than being the background, object, or container for learning that is entirely determined by human design and interpretation.

\section{Fourth Proposition: Set protocols for experimenting wildly}

Our project began with a relatively tight series of protocols for selecting a single concept and a specific location and set of activities for experimenting with matter and movement. Nonetheless, the actual learning processes that emerged from these protocols turned out to be wildly experimental and productive for creative thinking and dialogue. The rigidity of the initial protocols also allowed us to analyse and assemble the four concepts and associated practices into a diagrammatic sequence, which gave the project more consistency as a modelling of environmental arts pedagogy. What is crucial in this proposition is the design of constraints that support open-ended learning processes and novel forms of participation.

\section{Fifth Proposition: Fold cartographic practices into the learning process}

In each of the conceptual experimentations that we engaged in this project, we can see that cartographic practices of mapping and documentation were embedded into the actual process of learning. We mapped corridors by drawing in the sand with a stick; we mapped flight with six word memoirs and photographs; our experimentations with viscosity were mapped by a camera placed beneath the surface; and our engagement with construction was mapped through the drawings that were created. Each of these cases demonstrates how the mapping and documentation of the learning process was folded into the process itself. This reveals ways that cartographic processes can increase the aesthetic, material, and conceptual yields of a given learning activity, allowing the experience to be translated through aesthetic renderings, conceptual diagrams, and material transductions of the learning process.

We hope that these five propositions are both provocative and useful for those seeking to develop an environmental arts pedagogy for engaging children with movement and materiality, or with any 
number of other concepts, issues, questions, or concerns about the changing environmental conditions of our times. As we continue to experiment with the relations between concepts, environments, pedagogies, artworks, bodies, spaces, technologies, and times, we note the urgency of finding ways to co-inhabit the world more artfully, more relationally, more sensitively, and more experimentally.

\section{References}

Alaimo, S. \& Hekman, S.J. (Eds.). (2008). Material feminisms. Bloomington: Indiana University Press.

Alaimo, S. (2010). Bodily natures: Science, environment, and the material self. Bloomington: Indiana University Press.

Braidotti, R. (2013). The posthuman. Cambridge, UK: Polity Press.

Coole, D., \& Frost, S. (2010). Introducing the New Materialisms. In D. Coole \& S. Frost (Eds.), New Materialisms: Ontology, Agency and Politics (pp. 1-43). London, UK: Duke University Press.

Barad, K. (2007). Meeting the universe halfway: Quantum physics and the entanglement of matter and meaning. Durham, NC \& London: Duke University Press.

Bennett, J. (2010). Vibrant matter: A political ecology of things. Durham, NC: Duke University Press.

Cahill, H., Coffey, J., \& Smith, K. (2016). Exploring embodied methodologies for transformative practice in early childhood and youth. Journal of Pedagogy, 7(1), 79-92.

Davies, M. (2003). Movement and dance in early childhood. Surrey, UK: Sage.

de Freitas, E. (2012). The classroom as rhizome: New strategies for diagramming knotted interactions. Qualitative Inquiry, 18(7), 557-570.

Deleuze, G. (1994). Difference \& repetition. (P. Patton, Trans.). New York: Columbia University Press.

Deleuze, G., \& Guattari, F. (1987). A thousand plateaus: Capitalism and schizophrenia. (B. Massumi, Trans.). Minneapolis: University of Minnesota Press.

Garoian, C. R. (2012). Sustaining sustainability: The pedagogical drift of art research and practice. Studies in Art Education, 53 (4), 283-301.

Guattari, F. (1995). Chaosmosis: An ethico-aesthetic paradigm. Sydney, NSW: Power Publications.

Hunt, S. (2014). Ontologies of Indigeneity: the politics of embodying a concept. Cultural Geographies, 21(1), 27-32.

Ingold, T. (2007). Lines: A brief history. London: Routledge.

Ingold, T. (2011). Being alive: Essays on movement, knowledge and description. Oxon, UK: Routledge. Irwin, R. L. (2013). Becoming a/r/tography. Studies in Art Education. 54(3), 198-215.

Irwin, Rita L. \& Springgay, S. (2008). A/r/tography as practice based research. In Springgay, Stephanie, Irwin, Rita L., Leggo, Carl \& Gouzouasis, P. (Eds.). Being with A/r/tography (pp. xiii-xxvii). Rotterdam, The Netherlands: Sense Publishers. 
Irwin, R. L, \& O'Donoghue, D. (2012). Encountering pedagogy through relational art practices. International Journal of Art and Design Education, 31(2), 220-236.

Irwin, R. L. (2008). Communities of a/r/tographic practice. In S. Springgay, R.L. Irwin, R., C. Leggo, \& P. Gouzouasis (Eds.), Being with A/r/tography (pp. 71-80). Rotterdam, the Netherlands: Sense Publishers.

Irwin, R. L, \& Springgay, S. (2008). A/r/tography as practice-based research. In S. Springgay, R.L. Irwin, R., C. Leggo, \& P. Gouzouasis (Eds.), Being with A/r/tography (pp. xix-xxxiii). Rotterdam, the Netherlands: Sense Publications.

Knight, L. (2016). Playgrounds as sites of radical encounters: Mapping material, affective, spatial, and pedagogical collisions. In N. Snaza, D. Sonu, S.E. Truman, \& Z. Zaliwska (Eds.), Pedagogical Matters: New materialism and curriculum studies (pp. 13-28). New York: Peter Lang.

Koch, S. C., Caldwell, C., \& Fuchs, T. (2013). On body memory and embodied therapy. Body, Movement and Dance in Psychotherapy, 8(2), 82-94.

Kumagai, N., Sasajima, S., \& Ito, H. (1978). Long-term creep of rocks (results with large specimens obtained in about 20 years and those with small specimens in about 3 years). Journal of the Society of Materials Science, 27(293), 155-161.

Lenz Taguchi, H. (2016). "The Concept as Method": Tracing-and-mapping the problem of the neuro $(n)$ in the field of education. Cultural Studies<-> Critical Methodologies, 16(2), 213-223.

Manning, E., \& Massumi, B. (2014). Thought in the Act: Passages in the Ecology of Experience. Minneapolis: University of Minnesota Press.

Manning, E. (2013). Always more than one: Individuation's dance. Durham, NC: Duke University Press.

Manning, E. (2015). Artfulness. In R. Grisin (Ed.), The Nonhuman Turn (pp. 45-80). Minneapolis: University of Minnesota Press.

Massumi, B. (2011). Semblance and Event: Activist philosophy and the occurrent arts. Cambridge, MA: Massachusetts Institute of Technology.

Mies, M., \& Shiva, V. (1993). Ecofeminism. London, UK: Zed Books.

Morton, T. (2013). Hyperobjects: Philosophy and ecology after the end of the world. Minneapolis: University of Minnesota Press.

Pacini-Ketchabaw, V., Kind, S., \& Kocher, L. M. (2017). Encounters with materials in early childhood education. New York: Routledge.

Rousell, D. (2016). Dwelling in the Anthropocene: Reimagining university learning environments in response to social and ecological change. Australian Journal of Environmental Education, 32(02), 137-153.

Rousell, D. \& Fell, F. (in press). Becoming a work of art: Collaboration, materiality and posthumanism in tertiary visual arts education. The International Journal of Education Through Art [Special Issue on Speculative Realisms and Materialisms].

Saldanha, A. (2008). The political geography of many bodies. In K. Cox, M. Low, \& J. Robinson (Eds.), The SAGE Handbook of Political Geography (pp. 323-334). London: Sage. 
Springgay, S. \& Rotas, N. (2015). How do you make a classroom operate like a work of art? Deleuzeguattarian methodologies of research-creation. International Journal of Qualitative Studies in Education, 28(5), 552-272.

Springgay, S., \& Zaliwska, Z. (2015). Diagrams and cuts: A materialist approach to researchcreation. Cultural Studies <-> Critical Methodologies, 15(2), 136-144.

St. Pierre, E.A. (2016). Curriculum for new material, new empirical inquiry. In N. Snaza, D. Sonu, S.E. Truman, \& Z. Zaliwska (Eds.), Pedagogical matters: New materialisms and curriculum studies (pp. 112). New York, NY: Peter Lang.

Stengers, I. (2005). Introductory Notes on an Ecology of Practices. Cultural Studies Review. 11(1), 183-196.

Triggs, Valerie \& Irwin, Rita L. (in press). Pedagogy and the A/r/tographic Invitation. In R. Hickman (Ed). The International Encyclopedia of Art and Design Education. Wiley-Blackwell.

Ulmer, J. B. (2015). Embodied writing: choreographic composition as methodology. Research in Dance Education, 16(1), 33-50.

Watson, J. (2009). Guattari's diagrammatic thought: Writing between Lacan and Deleuze. London, UK: Bloomsbury.

Whitehead, A.N. (1978). Process and reality. New York: The Free Press. 